\title{
Suicide in the World: an Overview of Prevalence and Its Risk Factors
}

Eugênia Rodrigues Ferreira ${ }^{1}$, Rafael Gomes Aragão1, Jordanna de Fátima Moraes Reis ${ }^{1}$, Greyce Ellen Neres Reis ${ }^{1}$, Franciely Ferreira Santana ${ }^{1}$, Maria Nizete Tavares Alves ${ }^{2}$, Janaina Carvalho Braz Macêdo ${ }^{3}$, Uilna Natercia Soares Feitosa ${ }^{4}$, Carmem Ulisses Peixoto ${ }^{4}$, Maria Eliana Pierre Martins ${ }^{4}$, José Leandro de Almeida Neto ${ }^{5}$, Modesto Leite Rolim Neto ${ }^{1}$

\section{Abstract}

Suicide is a complex and multi-causal phenomenon, thats why it can't be understood in a generalized way, but in different profiles such as gender, age, social support and other psychiatric disorders. It is a major public health problem worldwide and more than 1 million people die from suicide every year. This world problem demands hybrid preventive acts in several aspects, such as social, interpersonal and from the government.

Suicide is a social factor of high frequency and especially in the male population [1, 2]. It is a major public health problem worldwide and more than 1 million people die from suicide every year $[3,4]$. In some countries, like Spain, suicide is the first cause of unnatural death, surpassing deaths from road accidents. $[5,6]$ The suicide attempt was defined as self-injurious behavior with a nonfatal outcome, justified by the leakage of personal and social difficulties. It appears in different aspects such as the extent of the liability wish to die verses the active intention to attempt suicide; the subjective sense of control of suicidal thoughts, attributed the causes to act or the planning phase. This past behavior of the implementation of suicide, of which half of the cases die on the first try. [7]

The death of an emotionally close person, conflicts within the family, relationship problems and violence [8], comorbid alcohol dependence, comorbid anxiety disorder, hopelessness, [7] and marital dissolution or divorce (This is evident in the high correlation between aggregate divorce and suicide rates as well as the higher risk of suicide among divorced populations compared to their married counterparts
1 Faculty of medicine estacio FMJ, Juazeiro do Norte, Ceará, Brazil.

2 Nursing Course, Regional University Cariri - URCA, Crato, Ceará, Brazil.

3 Basic Health, Health's Secretary of Juazeiro do Norte, Ceará, Brazil.

4 Post Graduate in Science of Health, Faculty of Medicine ABC, Santo André, São Paulo, Brazil.

5 Faculty of Applied Sciences - Dr. Leão Sampaio, Juazeiro do Norte, Ceará, Brazil.

\section{Contact information:}

Modesto Leite Rolim Neto.

” modestorolim@yahoo.com.br

\section{Keywords}

Suicide; Risk Factors;

Prevalence. 
in population-level studies) [9] are the main reasons why suicide attempt are shown.

Suicidal ideation and suicide attempts are important indicators of emotional distress. [10] Some sick (such as those suffering from depression, personality disorders, schizophrenia, cancer, HIVIAIDS, Huntington's disease, multiple sclerosis, epilepsy, peptic ulcer, renal disease, spinal cord injury, systemic lupus erythematosus) $[11,12]$ and victims of prejudice, for example, only feel the needing to communicate the suicide desire when that comes from its own initiative, which does not occur when they are put in pressure situations, such as formal interviews. Most contacts with Major Depressive Distress patient soccur in primary health care, but in this setting suicidal ideation may often go unnoticed [7].

Risk factors for suicide and suicide attempt may not be universal. For this reason, culturally informed preventive strategies that enable improved assessment of risk factors across diverse populations are needed. [13]

Suicide is a complex and multi-causal phenomenon [1], thats why it can't be understood in a generalized way, but in different profiles such as gender, age, financial and social support and other psychiatric disorders.

\section{The difference between gender and the suicide risk}

From an epidemiological point of view, suicidal behavior differs strongly between genders, is subject to many public misconceptions worldwide affects individuals and societies both directly and indirectly due to the personal and financial losses that it causes and has been described as one of the most extreme life situations that a person can encounter [8, 14-17]. Similar proportions of men and women report having made a plan for suicide. Women are significantly more likely than men to make a suicide attempt. The proportion of those with ideation who make a suicide attempt is $41.4 \%$ for women and $33.2 \%$ for men, in accordance with the Western cultures, suicidal ideation is more common among females in all age groups (except for those aged over 65). [18, 19]

On the other hand, there are studies that show the prevalence of suicidal behavior in the male population. Three variables assessed were significantly associated with suicide attempts in the past 12 months among males: psychological distress; alcohol misure as assessed by the CAGE; and experiencing physical violence during adulthood. [20] Only $19 \%$ of men and $6 \%$ of women who made their index attempt by cutting or piercing used the same method when they completed suicide. Finally, increase in the seriousness of an SA (e.g., number of drugs ingested, dose ingested), from one attempt to the next, has previously been found to be associated with enhanced risk for subsequent suicide among self-poisoning adults. Joiner suggested previous suicidal behavior serves as a form of "practice" for future suicidal behavior and that individuals "improve" their ability to engage in suicidal behavior with repetition, thus increasing the risk of completed suicide. [21-24]

\section{Age as a risk factor for suicide}

Suicide is a tragic event, and is one of the leading causes of death among adolescents; however, it is potentially preventable. Adolescents are known to be vulnerable to self harm or suicide attempts, and to be at increased risk of emotional instability and impulsive behaviors. [25]

Reviews of studies conducted in clinical and community samples suggest that up to $42 \%$ of adolescents Who attempt suicide go on to make another attempt within 2 years of their original attempt, with girls who attempt suicide in adolescence at higher risk of repetition than boys. Repeated suicide attempts (SAs) are, in turn, associated with higher rates of psychiatric diagnosis, particularly major depression, and with difficulties in emotion regulation, hopelessness, and risk for further SAs. Adolescents who made repeat SAs during the follow-up period 
did not differ from those who did not make a repeat attempt in features of their index SA, including wish to die, whether the attempt was planned, medical seriousness of the SA, and on an overall score reflecting suicidal intent. It was made semistructured interview that assesses characteristics of teenagers most recent SA. Adolescents who report a history of any past SAs (i.e., respond "yes" to the question, Have you ever tried to kill yourself?). Areas of inquiry include method, precipitating events, warnings/threats. [21, 26-35]

Thefore, the significant incidence and consecutive repetitions of attempted suicide show that this age group and this emotional instability can be analyzed as a risk factor for suicide and needs reflections on this issue.

Rapid aging worldwide challenges the existing social setting by putting additional strains on social security systems, increasing demands for health care, and the persisting negative attitudes toward older people in our society [36-39]. In 2000, the World Health Organization estimated the rates of suicide in men and women, aged 75 years and older, to be 50 and 16 per 100 000, respectively, indicating a clear relationship between increased suicide rates with age. As in other age groups, suicide in older people involves a complex interaction between psychiatric, psychological, physical, social and cultural factors. [40-45]

\section{Social support in suicide prevention}

Many studies show that suicidal behavior is caused by the low engagement in society and little social support, such as dialogues and sharing the everyday's difficulties. Social support is a key psychological and sociological concept related to social bonds and mutual helping. [46] A more recent explanatory model of suicide is the stress-diathesis model that identifies cognitive and social factors as necessary antecedents that increase vulnerability to stress, followed by stressful life events that trigger suicidal behavior. [47]
A high level of social support decreases the risk of suicide. Shortage of social support increases mortality risk, health problems and depressive symptoms in the elderly. [46, 48-52] Durkheim's classic sociological theory on suicide purports that modern urban life disrupts social cohesion/integration resulting in a greater risk of suicide. [47] Reported a significant protective effect of high social support, and interpersonal skills. Similarly, observed a significant protective effect of discussing difficulties with friends and family, positive emotional health, and connectedness to family. [20, 53-54] Family should be the main provider of care [36] fracturing of family systems and a consequent struggle to meet role obligations, all of which contribute to poor mental health and suicide [47] In addition, participants who reported a poor relationship with family were almost four times more likely to attempt suicide. [47] In fact, it was social stressors that appeared to be providing the added stimulus behind suicide attempts. [47]

Among the potential protective factors frequently discussed in qualitative research on suicide prevention in indigenous health are participation in traditional activities, and the cultural relevance of prevention programs and services. [20, 55-59] The social situation of different age groups varies across countries and it could be explained by differences in cultural, political, and socio -economic context- by welfare state. [36] This study shows that [60] there is a statistical difference with suicide intent on living alone, impulsivity and mental disorder [60] and communication is a protectable factor for suicide intent. [60]

In addition to the family and social issues, socioeconomic status reflect in the rates of suicide. It has long been recognised that periods of economic uncertainty are associated with rises in suicide. Durkheim hypothesised that key societal forces such as social integration can be disrupted by factors related to economic downturn which consequently have an impact on suicide rates. Amongst a ran- 
Vol. 8 No. 186 doi: $10.3823 / 1785$ ge of other stressors recessions lead to increases in debt, job losses, house repossession, strains on relationships and reductions in public spending, which in turn adversely affect mental health, [6164] which increases the suicidal rates.

Failure of social integration, such as unemployment, isolation and divorce, has been viewed as a weakness of the network between the individual and society, and has been repeatedly indicated to be an important cause of suicide. When the severity of suicidal ideation was high, the degree of receiving and providing social support decreased significantly, and strong feelings of dissatisfaction with social support emerged. [46]

\section{Depression and suicide risk}

Psychiatric diagnosis is found in almost all cases of suicidal behavior and attempts of suicide. Risk factors for suicide attempts included psychological distress, violence, sexual abuse, and substance use, with gender differences in exposure to certain risk factors and correlation with suicide attempts. [20] The strongest overall risk factor for suicide was depression [3] and the risk of suicide was consistently highest after a diagnosis of depression. [3] (Some studies noticed that) a diagnosis of depression was found in $33 \%$, and depressive mood/symptoms in $47 \%$ of cases (of suicide). About $55 \%$ had a physical health. Psychosocial factors commonly associated with suicide attempt include depression and anxiety. [20-65-69]

Beyond of depression, other psychiatric diseases can be easily found in cases of suicide, like PostTraumatic Stress Disorder (PTSD) and anxiety. [7072] Previous studies have found mental disorders (e.g., affective disorder, personality disorder, and major depressive disorder) to be significantly associated with suicidality. The association between PTSD symptoms and suicide ideation or behavior still remains unclear. One perspective is that it is not PTSD per se, but the co-occurrence of PTSD with other psychiatric disorders, especially depression, that leads to suicidality. In a study of four communities exposed to Hurricane Mitch in Nicaragua, researchers found that individuals with a PTSD diagnosis reported significantly higher levels of suicide ideation $(37.9 \%)$ than those without a PTSD diagnosis $(9.0 \%)$. In a study of adolescents who had experienced the threat of mudslides caused found that PTSD had both direct and indirect (via major depressive disorder) effects on an increased suicide risk. [70-72]

The risk of mental disorder and PTSD is elevated among those exposed to any conflict related traumatic event compared to those exposed only to non-conflict related traumatic events. [18, 73] Many are the reasons why people develop psychiatric disorders. Being a part of a minority class is one of them, for instance. [Studies show that] minority specific stressors cause mental health problems, including suicidality, [because] living in a State with discriminatory laws has a negative impact on the mental health of [10] minority individuals. [10] [It's important to note that some studies] points to important gender differences with regard to exposure to psychosocial risk factors for suicide. A significantly greater percentage of women had experienced sexual abuse and physical violence. e.g. [20] Thus, we must be aware for any signs of depression or another psychological distress, because these conflicts can result in a serious suicidal thoughts or attempts of suicide, and we need to take preventive measures as soon as possible, in order to prevent any imminent tragedy against life.

Thus, suicide is a growing health problem worldwide. The absolute number of deaths from suicide is likely to rise. [20] This world problem demands hybrid preventive acts in several aspects, such as social, interpersonal and from the government. To develop appropriate suicide prevention strategies is important to improve our understanding of factors associated with suicidal ideation and attempts. [47] Understanding the factors contributing to this 
emerging problem and developing effective latelife suicide prevention programmes is therefore an international priority. [20]

Risk factors are identifiable and can serve as warning signs before the suicidal act, allowing for time to anticipate and apply appropriate intervention to prevent suicidal behavior. [13] Targeting primary care providers where late-life depression and physical illness can be detected and treated is a potential strategy to address late-life suicide. [20]

The association of depression and suicide in older people was the most consistent finding in the 18 studies that reported on psychiatric diagnoses problem, [20] and the effect of depression on suicide risk was strongest among older adults. [3] Depression can also be associated with terminally diseases, like cancer. Successful antidepressant treatment for cases of terminally ill cancer patients with major depression, suicidal ideation and a desire for death has been reported, [40] but not in all ages. Terminal illness was associated with only a small proportion of older people who completed suicide in these studies. [20]

A lot of different studies try to explain these suicidal behaviors and attempts of suicide. It's noticeable that the goal of many cohort studies is a detailed view of clinical and evolution of patients with depression in terms of recovery, chronicity and recurrence, suicidal behavior and functional disability. [7] Beyond emotional distress, we found other causes of suicidal attempts, such as: Living alone may be another factor related to suicide with high intent. Somebody who lived alone was in the lack of communication with others. [60] Aging, unnemployment and educations are also strong suicidal risk factors. Most women and men who died from suicide were between 35 and 64 years old and they were more likely to be unmarried, have the lowest educational attainment, be non-employed and have lower incomes. [3] On the other hand, we have missing social support as a strong factor that leads people to suicidal behavior. Various dysfunctions of social relationships have been proposed as a cause of suicide. [46]

Poisoning can also be understood as a potential risk factor for suicidal behavior. Self-poisoning by lethal pesticides is commonly used in acts of suicide. Some studies showed that the increased use of pesticides is associated with an increase in suicides in China [60].

Many studies noticed as well that some people don't have the real intention of death, which shows that they act on impulsivity. Impulsivity is an important factor and can be a predictor for suicide.

Interventions suicide prevention for the population should address not only individual mental health and substance abuse support needs but also the overwhelming poor psychosocial conditions. Many are the reasons for suicidal thoughts and suicidal behavior all around the world, that's why identifying risk and protective factors in a given population is a crucial step towards the development and implementation of suicide risk assessment and management strategies. [47]

Therefore we conclude that the welfare states shape the context and exercise influence on the subjective well-being, and thus may lead to variations in suicide risk at the individual level. [36]

According to the Centers for Disease Control and Prevention (CDC), there were 34,598 suicide deaths in the US in 2007, 11.5 per 100,000 people, making suicide the eleventh leading cause of death in the United States (Centers for Disease Control and Prevention (CDC) [74]. In richer countries, three times as many men die of suicide than women do, but in low- and middle-income countries the male-tofemale ratio is much lower at 1.5 men to each woman. [75] So, suicide is a growing health problem worldwide. The absolute number of deaths from suicide is likely to rise. [20]

This world problem demands hybrid preventive acts in several aspects, such as social, interpersonal and from the government. To develop appropriate suicide prevention strategies is important to impro- 
ve our understanding of factors associated with suicidal ideation and attempts. [47] Understanding the factors contributing to this emerging problem and developing effective late-life suicide prevention programmes is therefore an international priority. [20] Risk factors are identifiable and can serve as warning signs before the suicidal act, allowing for time to anticipate and apply appropriate intervention to prevent suicidal behavior. [13] Targeting primary care providers where late-life depression and physical illness can be detected and treated is a potential strategy to address late-life suicide. [20]

Suicidal ideation and suicide attempts are important indicators of emotional distress [10]; We report relative risks of suicide in the [3] population based on more completely ascertained psychiatric diagnoses. [3] But not in all the countries. Chinese suicides have low prevalence of mental disorders and it's suicide rates have been decreased, [60] for example. We further showed that the risk of suicide was consistently highest in the [3] diagnosis of depression. [3] The association of depression and suicide in older people was the most consistent finding in the 18 studies that reported on psychiatric diagnoses problem, [20] and the effect of depression on suicide risk was strongest among older adults. [3] Depression can also be associated with terminaIly diseases, like cancer. Successful antidepressant treatment for cases of terminally ill cancer patients with major depression, suicidal ideation and a desire for death has been reported, [40] but not in all ages.

Terminal illness was associated with only a small proportion of older people who completed suicide in these studies. [20] A lot of different studies try to explain these suicidal behaviors and attempts of suicide. It's noticeable that the goal of many cohort studies is a detailed view of clinical and evolution of patients with depression in terms of recovery, chronicity and recurrence, suicidal behavior and functional disability. [7]

Beyond emotional distress, we found other causes of suicidal attempts, such as: Living alone may be another factor related to suicide with high intent. Somebody who lived alone was in the lack of communication with others. [60] Aging, unnemployment and educations are also strong suicidal risk factors. Most women and men who died from suicide were between 35 and 64 years old and they were more likely to be unmarried, have the lowest educational attainment, be non-employed and have lower incomes. [3] On the other hand, we have missing social support as a strong factor that leads people to suicidal behavior. Various dysfunctions of social relationships have been proposed as a cause of suicide. [46] Poisoning can also be understood as a potential risk factor for suicidal behavior. Self-poisoning by lethal pesticides is commonly used in acts of suicide. Some studies showed that the increased use of pesticides is associated with an increase in suicides in China. Many studies noticed as well that some people don't have the real intention of death, which shows that they act on impulsivity. Impulsivity is an important factor and can be a predictor for suicide.

In China, about $50 \%$ of suicide attempt can be categorized as impulsivity suicide. This study showed that the [60] impulsivity killed some Chinese rural young men and women who did not really want to die by suicide. [60] Interventions suicide prevention for the population should address not only individual mental health and substance abuse support needs but also the overwhelming poor psychosocial conditions. Many are the reasons for suicidal thoughts and suicidal behavior all around the world, that's why identifying risk and protective factors in a given population is a crucial step towards the development and implementation of suicide risk assessment and management strategies. [47] Therefore we conclude that the welfare states shape the context and exercise influence on the subjective well-being, and thus may lead to variations in suicide risk at the individual level. [36] 


\section{References}

1. Ceccon RF, Meneghel SN, Tavares JT, Lautert L. Suicídio e trabalho em metrópoles brasileiras: um estudo ecológico. Ciência \& Saúde coletiva 2014; 19(7): 2225-2234.

2. Durkheim E. O Suicídio - Um Estudo Sociológico. Rio de Janeiro: Zahar Editores; 1982

3. Crump C, Sundquist K, Sundquist J, Winkleby MA. Sociodemographic psychiatric and somatic risk factors for suicide: a Swedish national cohort study. Psychol Med 2014; 44: 279-289.

4. Bailey RK, Patel TC, Avenido J, Patel M, Jaleel M, Barker NC, Khan JA, Ali S, Jabeen S. Suicide: current trends. Journal of the National Medical Association 2011; 103: 614-617.

5. Sáiz PA, Bobes J. Prevención del suicidio en España: uma necesidad clínica no resuelta. Rev Psiquiatr Salud Ment 2014; 7(1): 1-4

6. Instituto Nacional de Estadística. Disponible en: http:// www.ine.es/jaxi/menu.do?type $=$ pcaxis $\&$ path $=/$ t15/p417/ a2012/\&file $=$ pcaxis

7. Vuorilehto M, Valtonen HM, Melartin T, Sokero P, Suominen K, Isometsä ET. Method of assessment determines prevalence of suicidal ideation among patients with depression. Eur Psychiatry 2014; 29: 338-344

8. Eisenwort B, Till B, Hinterbuchinger B, Niederkrotenthaler T. Sociable, Mentally Disturbed Women and Angry, Rejected Men: Cultural Scripts for the Suicidal Behavior of Women and Menin the Austrian Print Media. Sex Roles 2014; 71: 246-260.

9. Yip, PS F, Yousuf, S, Chan CH, Yung T, Wu KCC. The roles of culture and gender in the relationship between divorce and suicide risk: a meta-analysis. Soc. Sci. Med 2015; 128: 87-94.

10. Baioco R. Ioverno S, Cerutti R, Santamaria F, Fontanesi L, Lingiardi $V$, et al. Suicidal ideation in Spanish and Italian lesbian and gay young adults: The role of internalized sexual stigma. Psicothema 2014; 26(4): 490-496.

11. Yolanda T, González-Villar A, Gómez-Perretta C, Carrillo-de-laPeña MT. (2015). Suicidality in chronic pain: predictors of suicidal ideation in fibromyalgia. Pain Practice 2015; 15(4): 323-332.

12. Hawton K, van Heeringen K. Suicide. Lancet 2009; 373: 1372 1381

13. Teti GL, Rebok F, Rojas SM, Grendas L, Daray FM. Systematic review of risk factors for suicide and suicide attempt among psychiatric patients in Latin America and Caribbean. Rev Panam Salud Publica 2014; 36(2): 124-132.

14. Leach, M. M. Cultural diversity and suicide: ethnic, religious, gender, and sexual orientation perspectives. New York: Haworth Press 2006.

15. Niederkrotenthaler T, Voracek M, Herberth A, Till B, Strauss M, Etzersdorfer E, Eisenwort B, Sonneck G. Role of media reports in completed and prevented suicide: Werther v. Papageno effects. Brit J Psychiatr 2010; 197: 1-10.
16. World Health Organization. Preventing suicide: a resource for media professionals. Geneva: World Health Organization 2008.

17. Frankl, V. E. The unheard cry for meaning. New York: Touchstone 1978.

18. O'Neill S, Ferry F, Murphy S, Corry C, Bolton D, Devine B, et al. Patterns of Suicidal Ideation and Behavior in Northern Ireland and Associations with Conflict Related Trauma. PLoS ONE 2014; 9(3): e91532.

19. Nock MK, Borges G,Bromet EJ, Cha CB, Kessler RC, Lee S Suicide and Suicidal Behavior. Epidemiol Rev 2008; 30(1): 133-154.

20. Fraser SL, Geoffroy D, Chachamovich E, Kirmayer LJ. Changing Rates of Suicide Ideation and Attempts Among Inuit Youth: A Gender-Based Analysis of Risk and Protective Factors. Suicide and Life-Threatening Behavior 2015 Apr; 45(2): 141-156.

21. Miranda R, Jaegere $E$, Restifo $K$, Shaffer D. Longitudinal followup study of adolescents who report a suicide attempt: aspects of suicidal behavior that increase risk of a future attempt. Depression and anxiety 2014; 31: 19-26.

22. Runeson B, Tidemalm D, Dahlin M, Lichtenstein P, Langström $\mathrm{N}$. Method of attempted suicide as predictor of subsequent successful suicide: national long term cohort study. Br Med J 2010; 341: 3222.

23. Carter G, Reith DM, Whyte IM, McPherson M. Repeated selfpoisoning: increasing severity of self-harm as a predictor of subsequent suicide. Br J Psychiatry 2005; 186: 253-257.

24. Joiner TE. Why PeopleDie by Suicide. Cambridge, MA: Harvard University Press; 2005: 46-93.

25. Seung-Gul Kang, Yu Jin Lee, Seog Ju Kim, Weonjeong Lim, Heon-Jeong Lee, Young-Min, et al. Weekend catch-up sleep is independently associated with suicide attempts and self-injury in Korean adolescents. Comprehensive Psychiatry 2014; 55: 319-325.

26. Blakemore SJ. The social brain in adolescence. Nature reviews. Neurosciences 2008; 9: 267-77.

27. Hawton K, Saunders KE, O'Connor RC. Self-harm and suicide in adolescents. Lancet 2012; 379: 2373-82.

28. Bridge JA, Goldstein TR, Brent DA. Adolescent suicide and suicidal behavior. J Child Psychol Psychiatry 2006; 47: 372-394.

29. Lewinsohn PM, Rohde P, Seeley, JR. Adolescent suicidal ideation and attempts: prevalence, risk factors, and clinical implications. Clin Psychol Sci Pract 1996; 3: 25-46.

30. Lewinsohn PM, Rohde P, Seeley JR, Baldwin CL. Gender differences in suicide attempts from adolescence to young adulthood. J Am Acad Child Adolesc Psychiatry 2001; 40: 427434.

31. Miranda R, Scott M, Hicks R, Wilcox HC, Harris Munfakh JL, Shaffer D. Suicide attempt characteristics, diagnoses, and future attempts: comparing multiple attempters to single attempters and ideators. J Am Acad Child Adolesc Psychiatry 2008; 47: 3240. 
32. Esposito C, Spirito A, Boergers J, Donaldson D. Affective, behavioral, and cognitive functioning in adolescents with multiple suicide attempts. Suicide Life Threat Behav 2003; 33: 389-399.

33. Goldston D, Daniel S, Reboussin D, Reboussin B, Frazier P, Kelley A. Suicide attempts among formerly hospitalized adolescents: a prospective naturalistic study of risk during the first 5 years after discharge. J Am Acad Child Adolesc Psychiatry 1999; 38: 660671.

34. Hult'en A, Jiang G-X, Wasserman D, et al. Repetition of attempted suicide among teenagers in Europe: frequency, timing, and risk factors. Eur Child Adolesc Psychiatry 2001; 10: 161-169.

35. Grøholt B, Ekeberg O, Haldorsen T. Adolescent suicide attempters: what predicts future suicidal acts? Suicide Life Threat Behav 2006; 36: 638-650.

36. Jing Wu, Airi Värnik, Liina-Mai Toodin, Peeter Värnik, Kai Kasearu. Suicide among older people in relation to their subjective and objective well-being in different European regions. Eur J Ageing 2014; 11: 131-140.

37. Palmore EB Ageism: negative and positive. Springer 1999: New York.

38. Nelson TD Ageism: stereotyping and prejudice against older persons. MIT Press 2004, Cambridge.

39. Nelson TD Ageism: prejudice against our feared future self. J Soc Issues 2005; 61(2): 207-221.

40. Cheung G, Merry S, Sundram F. Medical examiner and coroner reports: uses and limitations in the epidemiology and prevention of late-life suicide. Int J Geriatr Psychiatry 2015: 1-12.

41. World Health Organization. 2002. Distribution of suicide rates (per 100,000) by gender and age. Available: http://www.who. int/mental_health/prevention/suicide/suicide_rates_chart/en/ index.html

42. Conwell Y, Van Orden K. Suicide in older adults. Psychiatr Clin North Am 2011; 34: 451-468.

43. Lapierre $S$, Erlangsen $A$, Waern $M$, et al. A systematic review of elderly suicide prevention programs. Crisis 2011 32: 89-98.

44. Erlangsen $A$, Nordentoft $M$, Conwell $Y$, et al. Key considerations for preventing suicide in older adults: consensus opinions of an expert panel. Crisis 2011; 32: 106-109.

45. Fässberg MM, Van Orden K, Duberstein P. A systematic review of social factors and suicidal behaviour in older adulthood. Int J Environ Res Publ Health 2012; 9: 722-745

46. Go Endo, Hirokazu Tachikawa, Yoshiharu Fukuoka, Miyuki Aiba, Kiyotaka Nemoto, Yuki Shiratori, et al. How perceived social support relates to suicidal ideation: A Japanese social resident survey. International Journal of Social Psychiatry 2014; 60(3): 290-298.
47. Armstrong $G$, Jorm AF, Samson $L$, Joubert $L$, Singh $S$, Kermode M. Suicidal ideation and attempts among men who inject drugs in Delhi, India: psychological and social risk factors. Soc Psychiatry Psychiatr Epidemiol 2014; 49: 1367-1377.

48. Ikeda, A., Iso, H., Kawachi, I., Yamagishi, K., Inoue, M., \& Tsugane, S. Social support and stroke and coronary heart disease: The JPHC study cohorts II. Stroke: A Journal of Cerebral Circulation 2008; 39: 768-775.

49. Poudel-Tandukar, K., Nanri, A., Mizoue, T., Matsushita, Y., Takahashi, Y., Noda, M., ... Tsugane, S. (2011). Social support and suicide in Japanese men and women: The Japan Public Health Center (JPHC)-based prospective study. Journal of Psychiatric Research 2011; 45: 1545-1550.

50. Berkman, L. F., \& Syme, S. L. Social networks, host resistance, and mortality: A nine-year follow-up study of Alameda County residents. American Journal of Epidemiology 1979; 109: 186204.

51. House, J. S., Robbins, C., \& Metzner, H. L. The association of social relationships and activities with mortality: Prospective evidence from the Tecumseh Community Health Study. American Journal of Epidemiology 1982; 116: 123-140.

52. Koizumi, Y., Awata, S., Kuriyama, S., Ohmori, K., Hozawa, A., Seki, T., Tsuji, I. Association between social support and depression status in the elderly: Results of a 1 year communitybased prospective cohort study in Japan. Psychiatry and Clinical Neurosciences 2005; 59: 563-569.

53. Howard-Pitney, B., Lafromboise, T. D., Basil, M., September, B., \& Johnson, M. Psychological and social indicators of suicide ideation and suicide attempts in Zuni adolescents. Journal of Consulting and Clinical Psychology 1992; 60: 473.

54. Borowsky, I. W., Resnick, M. D.,Ireland, M., \& Blum, R. W. Suicide attempts among American Indian and Alaska Native youth: Risk and protective factors. Archives of Pediatrics and Adolescent Medicine 1999; 153: 573-580.

55. Advisory Group on Suicide Prevention. Acting on what we know: Preventing youth suicide in First Nations. Ottawa: First Nations and Inuit Health Branch, Health Canada 2003.

56. Henderson, J., Mellin, C., \& Patel, F. Suicide-A statistical analysis by age, sex and method. Journal of Clinical Forensic Medicine 2005; 12: 305-309.

57. Kirmayer, L. J., Fraser, S.-L., Fauras, V., \& Whitley, R. Current approaches to aboriginal youth suicide prevention. Montreal: Culture and Mental Health Research Unit, Jewish General Hospital 2009

58. Middlebrook, D. L., Lemaster, P. L., Beals, J., Novins, D. K., \& Manson, S. M. (2001). Suicide prevention in American Indian and Alaska Native communities: A critical review of programs. Suicide and Life-Threatening Behavior 2001; 31: 132-s149.

59. Smye, V., \& Mussell, B. Aboriginal mental health-What works best. Vancouver: Mental Health Evaluation \& Community Consultation Unit, University of British Columbia 2001. 
60. 60-Long Sun, Jie Zhang. Characteristics of Chinese rural young suicides: Who did not have a strong intent to die. Comprehensive Psychiatry 2015; 57: 73-78.

61. Coope C, Gunnell D, Hollingworth W, Hawton K, Kapur N, Fearn V, et al. Suicide and the 2008 economic recession: Who is most at risk? Trends in suicide rates in England and Wales 20012011. Social Science \& Medicine 117 (2014): 76-85.

62. Durkheim, E. Suicide: a study in sociology, (originally published 1987). Routledge and Kegan Paul, London 1952

63. Morselli, H. Suicide: An Essay on Comparative Moral Statistics (originally published 1881). D. Appleton and Company, New York 1882

64. Swinscow, D., 1951. Some suicide statistics. Br. Med. J 1951; 1(4720): 1417-1423.

65. Borowsky, I. W., Resnick, M. D., Ireland, M., \& Blum, R. W. (1999). Suicide attempts among American Indian and Alaska Native youth: Risk and protective factors. Archives of Pediatrics and Adolescent Medicine 1999; 153: 573-580.

66. Howard-Pitney, B., Lafromboise, T. D., Basil, M., September, B., \& Johnson, M. Psychological and social indicators of suicide ideation and suicide attempts in Zuni adolescents. Journal of Consulting and Clinical Psychology 1992; 60: 473.

67. Kirmayer, L. J., Boothroyd, L. J., \& Hodgins, S. Attempted suicide among Inuit youth: Psychosocial correlates and implications for prevention. Canadian Journal of Psychiatry 1998; 43: 816-822.

68. 68-Lemaster, P. L., Beals, J., Novins, D. K., \& Manson, S. M. The prevalence of suicidal behaviors among Northern Plains American Indians. Suicide and Life-Threatening Behavior 2004; 34: 242-254.

69. Yoder, K. A., Whitbeck, L. B., Hoyt, D. R., \& Lafromboise, T. Suicidal ideation among American Indian youths. Archives of Suicide Research 2006; 10: 177-190.

70. Ying L, Chen C, Lin C, Greenberger E, Wu X, Jiang L. The Relationship Between Posttraumatic Stress Symptoms and Suicide Ideation Among Child Survivors Following the Wenchuan Earthquake. Suicide and Life-Threatening Behavior 2015 Apr; 45(2): 230-242.

71. Caldera, T., Palma, L., Penayo, U., \& Kullgren, G. Psychological impact of the hurricane Mitch in Nicaragua in a one-year perspective. Social Psychiatry and Psychiatric Epidemiology 2001; 36: 108-114.
72. Tang, T. C., Yen, C. F., Cheng, C. P., Yang, P., Chen, C. S., Yang, R. C., ET AL. Suicide risk and its correlate in adolescent who experienced typhoon induced mudslides: A structural equation model. Depression and Anxiety 2010; 27: 1143-1148.

73. Bunting BP, Ferry FR, Murphy SD, O'Neill SM, Bolton D Trauma associated with civil conflict and posttraumatic stress disorder: evidence from the Northern Ireland study of health and stress. J Trauma Stress 2013 26(1): 134-41.

74. Borges G, Orozco R, Rafful C, Miller E, Breslau J. Suicidality, ethnicity and immigration in the United States. Psychol Med. 2012 June; 42(6): 1175-1184.

75. Who. World Health Organization. Preventing suicide: a global imperative, 2014.

\section{Comment on this article:}

\section{f) (B) in $8+\mathbf{S}$.}

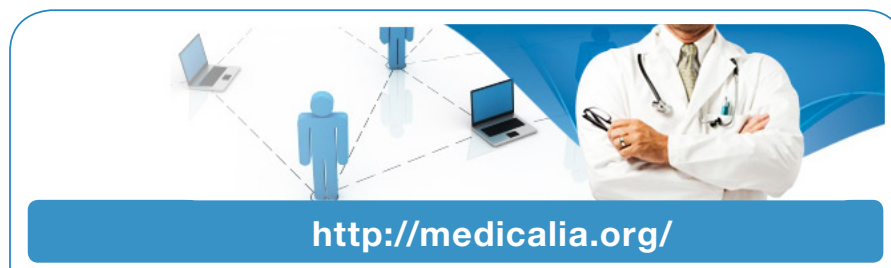

Where Doctors exchange clinical experiences, review their cases and share clinical knowledge. You can also access lots of medical publications for free. Join Now!

\section{Publish with iMedPub}

http://www.imed.pub

International Archives of Medicine is an open access journal publishing articles encompassing all aspects of medical science and clinical practice. IAM is considered a megajournal with independent sections on all areas of medicine. IAM is a really international journal with authors and board members from all around the world. The journal is widely indexed and classified Q1 in category Medicine. 